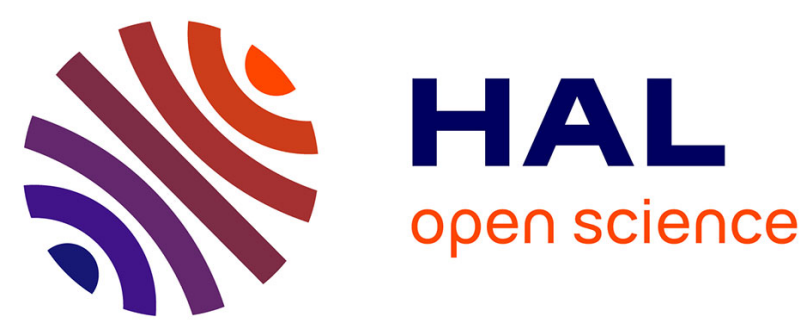

\title{
The chromosomal accommodation and domestication of mobile genetic elements
}

\author{
Marie Touchon, Louis-Marie Bobay, Eduardo P C Rocha
}

\section{To cite this version:}

Marie Touchon, Louis-Marie Bobay, Eduardo P C Rocha. The chromosomal accommodation and domestication of mobile genetic elements. Current Opinion in Microbiology, 2014, 22, pp.22-29. 10.1016/j.mib.2014.09.010 . pasteur-01122287

\section{HAL Id: pasteur-01122287}

\section{https://hal-pasteur.archives-ouvertes.fr/pasteur-01122287}

Submitted on 3 Mar 2015

HAL is a multi-disciplinary open access archive for the deposit and dissemination of scientific research documents, whether they are published or not. The documents may come from teaching and research institutions in France or abroad, or from public or private research centers.
L'archive ouverte pluridisciplinaire HAL, est destinée au dépôt et à la diffusion de documents scientifiques de niveau recherche, publiés ou non, émanant des établissements d'enseignement et de recherche français ou étrangers, des laboratoires publics ou privés.

\section{(1) (1) $\$$}

Distributed under a Creative Commons Attribution - NonCommercial - NoDerivatives| 4.0 


\section{The chromosomal accommodation and domestication of mobile genetic elements}

Marie Touchona,b, mtouchon@pasteur.fr

Louis-Marie Bobaya,b,c, louis-marie.bobay@pasteur.fr

Eduardo PC Rocha ${ }^{a, b, ~}{ }^{*}$, erocha@pasteur.fr

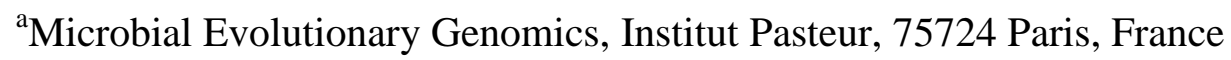

${ }^{\mathrm{b}} \mathrm{CNRS}$, UMR3525, 75724 Paris, France

${ }^{\mathrm{c}}$ Sorbonneuniversités, UPMC Univ Paris06, IFD, 4 place Jussieu, 75252 Paris cedex05, France.

* Corresponding author. Tel: +331 456833 53; Fax: +33 1442797 79; Email:

erocha@pasteur.fr; Present Address: Institut Pasteur, 25 rue du Docteur Roux, 75724 Paris

Keywords: Evolution, prokaryotes, viruses, comparative genomics.

\section{Abstract}

Prokaryotes are constantly being infected by large mobile genetic elements such as conjugative elements and temperate phages. The fitness of these elements is tightly linked with the evolutionary success of the host. This leads to selectionagainst disruptive effectstheir integration might have on the organization and structure of the chromosome. Seamless genetic accommodation of the mobile elements also involves silencing infectious mechanisms and expressing functions adaptive to the host. Ironically, these characteristics favor the host ability to domesticate the mobile element. Recent data suggests that the domestication of mobile elements might be frequent.Importantly, it might affect the evolution of chromosome organization and drive the diversification of social traits. 


\section{Introduction}

The genomes of Prokaryotes are extremely plasticbecause of the joint action of horizontal gene transfer (HGT) and differential gene loss [1-3]. Most genetic information arrives into the genome in large mobile genetic elements (MGEs), such as plasmids, integrative conjugative elements (ICEs) andtemperate phages [4,5]. These large elements are the focus of the present review. MGEs are important motors of bacterial adaptation,rapidly spreadingnew functions and social traits, even if they have short residence times in genomes [6].Several striking examples show the profound impact of MGEs. ICEsand insertion sequences make a third of the genomes of Orientiatsutsugamushi[7]. Certain genomes of Escherichia coli encode up to 18 prophages[8]. The symbiotic ICE of Mesorhizobium lotiis $~ 500 \mathrm{~kb}$ [9], which is more than certain bacterial chromosomes. The integration of such large genetic elements may impose a significant burden to the cell[10].The cost of transfer, in particular,leads to a trade-off between vertical and horizontal transmission [11]. Too much horizontal transfer decreases bacterial fitness and therefore vertical transmission. Infrequent transfer increases vertical at the cost of horizontal transmission. Importantly, both the element and the host are favored by the vertical transmission of host-MGE associations. The interaction between integrative MGE and the host is therefore favored when it leadsits smooth accommodation in the host genetic background.

\section{Chromosomal accommodation}

The genetic information encoded in prokaryotic chromosomes is highly organized [12](Figure 1). A very large fraction of the genome encodes genes or regulatory sequences needed for the interactions between the chromosome and cellular molecular machines. Since random MGE integration is likely to impose a fitness cost on the host, these elements have evolved strategies to integrate at permissive locations using sitespecific recombinases. MGEs integrating at ubiquitous highly conserved sequences are also more likely to find an integration site in another host and thus proliferateboth vertically and horizontally. Different mobile elements encoding closely related integrases tend to use the same integration regions in the chromosome. For example, the highly conserved tmRNAsite in Escherichia, Salmonella, and Klebsiellais an integrative hotspot for pathogenicity islands, prophages, and integrative conjugative elements. The high sequence conservation of stable RNA genes might contribute to the frequency with 
which they are used as integration sites[13,14]. Interestingly, several temperate phagesintegrate the genome of $E$. coli in intergenic regions that are highly conserved and used by other phages in Salmonella[15]. The high conservation of these non-coding sequences suggests the existence of selection for theirpreservation as integration sites. Since vertical replication is in general less costly than horizontal propagation,sitespecific integration might result from host-MGE co-evolution towards a seamless and reproducible accommodation of the mobile element.

Site-specific integration may facilitate the organization of genome plasticity in relation to the structure of the chromosome, which is highly condensed in the nucleoid to be able to fit the prokaryotic cell[16]. Depending on the methods and the species, chromosomes are structured at different scales that includemacrodomains( $>500 \mathrm{~kb})$ [17], chromosome interaction domains (30-420 kb, CID) [18], and negatively supercoiled loops (2-66kb)[19]. The association between chromosome structure and transcriptional networks renders gene expression dependent on chromosome organization [20]. In a similar way, chromosome structure is tightly linked with segregation [21]. The integration of MGEs alters the structure of the chromosome and might thus affect many cellular processes. While there are few reports on this subject, it has recently been observed that phage $\mathrm{Mu}$, which integrates almost randomly the chromosome, forms an autonomous stable chromosomal domain in E. coli [22]. This might facilitate transposition of the element and favor the expression of adaptive genes harbored by the prophage. Interestingly, phage lambda shows strong preference for integration at one very specific site in the chromosome and does not form a folding domain. It is tempting to speculate that MGEs integrating at specific sites in the chromosome, such as phage lambda,have co-evolved with the chromosome such that their integration does not lead to deleterious consequences in terms of chromosome structure. Elements integrating randomly in the chromosome, such as phage $\mathrm{Mu}$, must evolve ways of doing so without disturbing chromosomal structure, like producing autonomous structural units.

In E. coli and Salmonella, prophages tend to integrate at the macrodomains closer to the terminus of replication [15], even though this region encodes fewer typical integration targets such as stable RNA genes [23].Several MGEs even integrate specifically at difsites using the host Xer recombination system [24]. These patternssuggest that integration tropismand/or natural selection drive the large-scale distribution of MGEs in the 
chromosome. Integration of elements carrying their own recombinasescould be favored by DNA accessibility becauseTer-proximal macrodomainsare at the periphery of the $E$. coli nucleoid [25], or by the region of the chromosome closer to the infection site [26]. MGE integration sitescould also be counter-selectedin certain chromosomal regions. For example, MGEs integration close to highly expressed genes might be disfavored because transcription spillover from these genes into the MGE might reduce repression on its genes and favor excision and transfer. Accordingly, the tRNAs most frequently used as integration targets by E. coli phages are those corresponding to the rarer codons, which are also the least expressed [15]. Genes near the origin of replication are on average more expressed.They can also be over-expressed by replication-associated gene dosage effects, especially in periods of fast-growth or stress[23,27]. This may produce an effect similar to transcriptional spillover and explain why these regions usually encode few prophages. Non-lethalmobile elements, whose expression might be highly adaptive in certain circumstances,show different patterns of distribution. For example, pathogenicity islands concentrate in theorigin-proximal half of the E. coli chromosome (Figure 1). Finally, chromosomal genes flanking frequent MGE integration sites often have higher recombination rates [28,29], and this might lead to selection for integration close genes encoding specific functions. These few studies on the global and local patterns of distribution of MGEs suggest that site-specific integration has evolved towards loweringits disruptive effects on chromosome organization.Further studies will be required to disentangle the effects of integration tropism and natural selection on this co-evolutionary process.

MGEs endure selection to adapt to their genetic background. This involves the ability of the temperate phage to integrate and manipulate the host genetic networks. A classical example concerns the stress-induced excision of prophages and integrative conjugative elements by sensing the host SOS response [30,31]. Recent works have shown that the integration or manipulation of the host genetic networks by the MGE may stabilize its integrative state. For example, the stabilization of several prophagesin E. coli is under the control of the highly conserved transcriptional terminator Rho protein [32]. Several Staphylococcus aureusprophages are regulated by the host alternative $\sigma^{\mathrm{H}}$ factor, also involved in the regulation of natural competence[33]. The high mutation rates of prophages provide them with ample opportunity to avoid DNA motifs used by hosts to control their gene expression. The conservation of these regulatory dependencies 
suggests the existence of co-evolution between host and MGE to stabilize the integrative state. The integration of MGEs in the host genetic network allows them to regulate the trade-off between horizontal and vertical transmission in relation to cell physiology.

Adaptation to the genetic context of the host can also include selection for MGE-encoded DNA motifs associated with housekeeping cellular functions, such as chromosome replication, recombination, and segregation[34-36]. Accordingly, prophages closer to the terminus of replication are enriched in segregation-related motifs and those in the rest of the chromosome under-represent Ter-macrodomain associated motifs(Figure 1) [15]. The accommodation of MGEto the host chromosome by selecting for DNA motifs that are only relevant in the integrative state may superficially seem in contradiction with theirshort residence times in genomes. Yet, most well-studied integrative mobile elements have relatively narrow host ranges and integrate at the same genomic position in the different hosts.They will therefore endure the same type of selection pressures in the different hosts. This should favor their accommodation to the traits that are often encountered in its range of host chromosomes.

\section{Domestication of mobile elements}

MGEsencode many traits useful for the host. These traits increase indirectly the fitness of the element. Famously, many conjugative elements encode antibiotic resistance genes [37], and many phages provide toxins to bacterial pathogens [38]. In some cases it is unclear if a trait is directly advantageous to the MGE or if it is favored because it increases the host fitness. For example, someMGEs favor bacterial growth under certain conditions[39-41]. Interestingly, even costly core MGE functions, such as conjugation and transduction, can provide advantages to the host. Conjugative pili facilitate the formation of biofilms [42], and can be co-opted to secrete virulence factors to eukaryotic cells[43]. Horizontal transfer of the host DNA can occur by co-transfer with the MGE $[44,45]$. Occasional lysis caused by prophagesfavors the production of biofilms [46], promotes the bacterial adhesion to eukaryotic cell $[47,48]$, and acceleratesniche colonization by removing sensitive strains [49].

Genes encoding the mechanisms of horizontal transmissionare strongly repressed some time after transfer, presumably to lower theirburden on the host metabolism[50,51]. We have discussed above on how seamless integration of the MGE in the chromosome will lower its cost and therefore increase its fitness. Ironically, long-term repression of the 
genes encoding genetic mobilization poses a threat to MGE integrity because inactivating mutations may accumulate silently. Elementsrendered incapable of autonomous horizontal transmission are much more dependent on the host fitness and evolve predominantly towards favoring vertical transmission.

Silent genetic information is rapidly lost from bacterial lineages by a joint effect of a bias towards deletions and by selection against non-adaptive genesand pseudogenes $[1,3,52]$. Most prophages are able to excise and eventually kill the cell but many are incapable of producing autonomous infectious virions[8,48]. One would therefore expect strong selection for the rapid loss of these elements. Surprisingly, degraded prophages of $E$. coli and Salmonellaenterica evolve predominantly under strong purifying selection - most of the non-synonymous mutations occurring in prophagesare lost - suggesting that natural selection removes variants with inactivating mutations [53]. Importantly, this affects most strongly thegenes encoding phage housekeeping functions, like lysins and terminases, raising the intriguing possibility that bacteria may systematically select for phage-related functions in degraded genetic elements.

What could be the use of these domesticated phage functions? A sparse but long string of observations shows that inactive prophages or prophage-derived components can be adaptive[54]. They could favor horizontal gene transfer like transducing phages. They could antagonize other mobile elementslike many phages, either by competing with them[55], or by inhibiting their entry and expression [56]. They could also makevirionsunable to produce viable offspring but capable of killingsensitive competitors [54]. Finally, prophagesprovide many accessory functions, like adhesion, regulation, anddefense; several of which are used by bacteria in mutualistic or antagonistic interactions with eukaryotes[48,57-61]. Many of these functions require phage excision, transcription, and packaging, justifying why large fractions of prophages are under purifying selection. The organization of gene expression in phages around few large operons may also lead to counter-selection of gene inactivation to avoid polar mutations.

Elements under purifying selection are expected to remain in genomes for long periods of time. Yet, most phage integration events in E. coli are strain-specific, i.e., they occurred very recently[53,62]. How can prophages be under purifying selection when they are also frequently strain-specific? Many prophages may bring no adaptive value upon 
degradation and be rapidly lost, leaving only a small fraction of the prophagesaccumulating mutations. For the latter, the functional redundancy provided by multiple prophages may explain why they may undergo purifying selection and still be frequently lost. The constant afflux of prophages leads to a multiplicity of elements in genomes. This inevitably results in relaxed selection on elements that perform similar MGE-related functions; leading to frequent loss of prophage remnants that were previously under purifying selection. Most processes of mobile elements domestication are thus likely to be short-lived.

Nevertheless, examples of longstanding domestication of MGE machineries have been described (Figure 2). Many involve only one or a few genes, such as the acquisition of polymerases, lysins, resolvases or recombinases[63], leading to either analogous gene replacement, or to new variants of pre-existing functions. For example, prophageencoded Red $\beta$ recombinases in E. colicompensate the loss of the host recombination machinery while showinghigher processivityand tolerance to sequence divergence [64]. Domestication may also produce new sophisticated molecular machines[65].Conjugative systems have been many times domesticated as type IV protein secretion systems used both by pathogens and mutualists in their interactions with eukaryotes[66,67]. Plasmids have been domesticated as secondary chromosomes in several bacterial clades[68]. Phage-derived tail proteins are part of type VI secretion systems (T6SS) involved inantagonistic interactions with other bacteria and with eukaryotes[69]. Phages have also given rise to full-fledged tailocins(also called pyocins) involved in bacterial competitionor pathogenicity [70,71]. Gene transfer agents (GTA) encapsidate randomly the DNA of the bacterial genome (but not their own genome)and are thought to have derived from prophage domestication [72]. Many other observations show important, albeit mechanistically unclear, roles for MGE-derived structures. For example, phage tail-like structures produced by Pseudoalteromonasluteoviolaceatrigger the metamorphosis of a tubeworm [60].

\section{Conclusion}

Most recent very large-scale whole-genome studies have focused on the conserved parts of genomes. These are very helpful to understand epidemiological and mutational patterns but not how adaptation proceeds by horizontal gene transfer. New sequencing technologies producing longer reads should bring back the complete assembled genome 
as the standard in bacterial genomics. Larger datasets will facilitate the study of mobile elements accommodation in genomesincluding their subsequent domestication.They might also guide experimental testing of the many hypotheses that have been put forward regarding these subjects. Which functions often result from the domestication of mobile elements? Available data suggests that functions implicated in social evolution may predominatebecause mobile elements encode many secreted proteins[73], and complex symbiotic traits [74]. Machineries encoded by MGEs, or derived from them, are also used in bacterial warfare [75] and in symbiosis [47,76]. Understanding the fate of MGE in genomes is therefore likely to illuminate the constraints imposed by the structureof the chromosome on the dynamics of gene repertoires and also on the evolution of the social lives of bacteria. 


\section{Outstanding questions}

What is the impact of MGE integration on the chromosome structure?

What are the structural and evolutionary traits creating integration hotspots?

What are the main functions provided by domesticated MGE?

What are the rates of MGE domestication?

\section{Acknowledgements}

We thank members of our lab for discussions. Work in our laboratory is supported by an European Research Council starting grant [EVOMOBILOME ${ }^{\circ} 281605$ ] to EPCR, a grant from the Ministère de l'enseignementsupérieur et de la recherche to LMB, and funding from the CNRS and the Institut Pasteur. We apologize to the authors of studies we could not cite given space restrictions. 


\section{References}

1. Kuo $\mathrm{CH}$, Ochman $\mathrm{H}$ : The extinction dynamics of bacterial pseudogenes. PLoS Genet 2010, 6.

2. Treangen TJ, Rocha E: Horizontal transfer, not duplication, drives the expansion of protein families in prokaryotes.PLoS Genet 2011, 7:e1001284.

3. Koskiniemi S, Sun S, Berg OG, Andersson DI: Selection-driven gene loss in bacteria. PLoS Genetics 2012, 8:e1002787.

4. Frost LS, Leplae R, Summers AO, Toussaint A: Mobile genetic elements: the agents of open source evolution. Nat Rev Microbiol 2005, 3:722-732.

5. Cortez D, Forterre $\mathrm{P}$, Gribaldo S: A hidden reservoir of integrative elements is the major source of recently acquired foreign genes and ORFans in archaeal and bacterial genomes. Genome Biol 2009, 10:R65.

6. Rankin DJ, Rocha EPC, Brown SP: What traits are carried on mobile genetic elements, and why? Heredity 2011, 104:1-10.

7. Cho NH, Kim HR, Lee JH, Kim SY, Kim J, Cha S, Kim SY, Darby AC, Fuxelius HH, Yin J, et al.: The Orientia tsutsugamushi genome reveals massive proliferation of conjugative type IV secretion system and host-cell interaction genes. Proc Natl Acad Sci U S A 2007, 104:7981-7986.

8*. Asadulghani M, Ogura Y, Ooka T, Itoh T, Sawaguchi A, Iguchi A, Nakayama K, Hayashi $\mathrm{T}$ : The defective prophage pool of Escherichia coli 0157: prophageprophage interactions potentiate horizontal transfer of virulence determinants. PLoS Pathogens 2009, 5:e1000408.

This detailed study of the 18 prophages of Escherichia coli 0157:H7 Sakai shows that most prophages are defective at several levels (see also reference 48).

9. Sullivan JT, Ronson CW: Evolution of rhizobia by acquisition of a 500-kb symbiosis island that integrates into a phe-tRNA gene. Proc Natl Acad Sci U S A 1998, 95:5145-5149.

10*. Baltrus DA: Exploring the costs of horizontal gene transfer. Trends Ecol Evol 2013, 28:489-495.

An excellent review on the costs of horizontal gene transfer.

11. Haft RJ, Mittler JE, Traxler B: Competition favours reduced cost of plasmids to host bacteria. ISME J 2009, 3:761-769.

12. Rocha EPC: The organisation of the bacterial genome. Annu Rev Genet 2008, 42:211-233.

13. Williams KP: Integration sites for genetic elements in prokaryotic tRNA and tmRNA genes: sublocation preference of integrase subfamilies. Nucleic Acids Res 2002, 30:866-875.

14. Campbell A: Prophage insertion sites. Res Microbiol 2003, 154:277-282.

15*. Bobay LM, Rocha EP, Touchon M: The Adaptation of Temperate Bacteriophages to Their Host Genomes. Mol Biol Evol 2013, 30:737-751. 
Temperate phages adapt to the local and global organizational traits of the bacterial chromosome.

16. Ptacin JL, Shapiro L: Chromosome architecture is a key element of bacterial cellular organization. Cell Microbiol 2013, 15:45-52.

17. Valens M, Penaud S, Rossignol M, Cornet F, Boccard F: Macrodomain organization of the Escherichia coli chromosome. Embo J 2004, 23:4330-4341.

18. Le TB, Imakaev MV, Mirny LA, Laub MT: High-resolution mapping of the spatial organization of a bacterial chromosome. Science 2013, 342:731-734.

19. Postow L, Hardy CD, Arsuaga J, Cozzarelli NR: Topological domain structure of the Escherichia coli chromosome. Genes Dev 2004, 18:1766-1779.

20. Crozat E, Winkworth C, Gaffe J, Hallin PF, Riley MA, Lenski RE, Schneider D: Parallel genetic and phenotypic evolution of DNA superhelicity in experimental populations of Escherichia coli. Mol Biol Evol 2010, 27:2113-2128.

21. Espeli O, Borne R, Dupaigne P, Thiel A, Gigant E, Mercier R, Boccard F: A MatPdivisome interaction coordinates chromosome segregation with cell division in E. coli. Embo J 2012, 31:3198-3211.

22**. Saha RP, Lou Z, Meng L, Harshey RM: Transposable prophage Mu is organized as a stable chromosomal domain of E. coli. PLoS Genet 2013, 9:e1003902.

Shows that phage $\mathrm{Mu}$ is organized in an independent chromosome domain, whereas phage Lambda is not. The conformation of prophage $\mathrm{Mu}$ might facilitate random transposition and gene expression regulation.

23. Couturier E, Rocha EPC: Replication-associated gene dosage effects shape the genomes of fast-growing bacteria but only for transcription and translation genes. Mol Microbiol 2006, 59:1506-1518.

24. Das B, Martinez E, Midonet C, Barre FX: Integrative mobile elements exploiting Xer recombination. Trends Microbiol 2013, 21:23-30.

25. Meile JC, Mercier R, Stouf M, Pages C, Bouet JY, Cornet F: The terminal region of the E. coli chromosome localises at the periphery of the nucleoid. BMC Microbiol 2011, 11:28.

26*. Tal A, Arbel-Goren R, Costantino N, Court DL, Stavans J: Location of the unique integration site on an Escherichia coli chromosome by bacteriophage lambda DNA in vivo. Proc Natl Acad Sci U S A 2014, 111:7308-7312.

Lambda phage remains confined in the region of cell entry. Its integration seems favored by chromosomal movement at the time of DNA replication.

27. Slager J, Kjos M, Attaiech L, Veening JW: Antibiotic-induced replication stress triggers bacterial competence by increasing gene dosage near the origin. Cell 2014, 157:395-406.

28. Touchon M, Hoede C, Tenaillon O, Barbe V, Baeriswyl S, Bidet P, Bingen E, Bonacorsi $\mathrm{S}$, Bouchier $\mathrm{C}$, Bouvet $\mathrm{O}$, et al.: Organised genome dynamics in the Escherichia coli species results in highly diverse adaptive paths.PLoS Genet 2009, 5:e1000344. 
29*. Everitt RG, Didelot X, Batty EM, Miller RR, Knox K, Young BC, Bowden R, Auton A, Votintseva A, Larner-Svensson $\mathrm{H}$, et al.: Mobile elements drive recombination hotspots in the core genome of Staphylococcus aureus. Nat Commun 2014, 5:3956.

MGE increase the rate of recombination in chromosomal genes neighboring their integration sites in Staphylococcus aureus, a species with overall low recombination rates.

30. Beaber JW, Hochhut B, Waldor MK: SOS response promotes horizontal dissemination of antibiotic resistance genes. Nature 2004, 427:72-74.

31. Waldor MK, Friedman DI: Phage regulatory circuits and virulence gene expression. Curr Opin Microbiol 2005, 8:459-465.

32*. Menouni R, Champ S, Espinosa L, Boudvillain M, Ansaldi M: Transcription termination controls prophage maintenance in Escherichia coli genomes. Proc Natl Acad Sci U S A 2013, 110:14414-14419.

Regulation by Rho, an essential E. coli protein, stabilizes prophages.

33. Taо $\mathrm{L}, \mathrm{Wu} \mathrm{X}$, Sun $\mathrm{B}$ : Alternative sigma factor sigmaH modulates prophage integration and excision in Staphylococcus aureus. PLoS Pathog 2010, 6:e1000888.

34. Mercier R, Petit MA, Schbath S, Robin S, El Karoui M, Boccard F, Espeli O: The MatP/matS site-specific system organizes the terminus region of the $E$. coli chromosome into a macrodomain. Cell 2008, 135:475-485.

35. Tonthat NK, Milam SL, Chinnam N, Whitfill T, Margolin W, Schumacher MA: SImA forms a higher-order structure on DNA that inhibits cytokinetic Z-ring formation over the nucleoid. Proc Natl Acad Sci U S A 2013, 110:10586-10591.

36. Stouf M, Meile JC, Cornet F: FtsK actively segregates sister chromosomes in Escherichia coli. Proc Natl Acad Sci U S A 2013, 110:11157-11162.

37. Davies J, Davies D: Origins and evolution of antibiotic resistance. Microbiology and molecular biology reviews : MMBR 2010, 74:417-433.

38. Abedon ST, Lejeune JT: Why bacteriophage encode exotoxins and other virulence factors. Evolutionary Bioinformatics Online 2005, 1:97-110.

39. Edlin G, Lin L, Bitner R: Reproductive fitness of P1, P2, and Mu lysogens of Escherichia coli. J Virol 1977, 21:560-564.

40. Schuch R, Fischetti VA: The secret life of the anthrax agent Bacillus anthracis: bacteriophage-mediated ecological adaptations. PLoS One 2009, 4:e6532.

41*. Wang X, Kim Y, Ma Q, Hong SH, Pokusaeva K, Sturino JM, Wood TK: Cryptic prophages help bacteria cope with adverse environments. Nat Commun 2010, 1:147.

Shows the various cellular functions of cryptic prophage genes and their impact on bacterial physiology.

42. Ghigo JM: Natural conjugative plasmids induce bacterial biofilm development. Nature 2001, 412:442-445. 
43. Vogel J, Andrews $\mathrm{H}$, Wong S, Isberg R: Conjugative transfer by the virulence system of Legionella pneumophila.Science 1998, 279:873-876.

44. Uchiyama J, Takemura-Uchiyama I, Sakaguchi Y, Gamoh K, Kato SI, Daibata M, Ujihara T, Misawa N, Matsuzaki S: Intragenus generalized transduction in Staphylococcus spp. by a novel giant phage. ISME J 2014.

45. Lesic B, Zouine M, Ducos-Galand M, Huon C, Rosso ML, Prevost MC, Mazel D, Carniel E: A natural system of chromosome transfer in Yersinia pseudotuberculosis. PLoS Genet 2012, 8:e1002529.

46. Carrolo M, Frias MJ, Pinto FR, Melo-Cristino J, Ramirez M: Prophage spontaneous activation promotes DNA release enhancing biofilm formation in Streptococcus pneumoniae. PLoS One 2010, 5:e15678.

47. Mitchell J, Siboo IR, Takamatsu D, Chambers HF, Sullam PM: Mechanism of cell surface expression of the Streptococcus mitis platelet binding proteins $\mathrm{PblA}$ and PblB. Mol Microbiol 2007, 64:844-857.

48*. Matos RC, Lapaque N, Rigottier-Gois L, Debarbieux L, Meylheuc T, Gonzalez-Zorn B, Repoila F, Lopes Mde F, Serror P: Enterococcus faecalis prophage dynamics and contributions to pathogenic traits. PLoS Genet 2013, 9:e1003539.

Accurate analysis of the functionality of Enterococcusfaecalis prophages with a focus on the interactions between the different prophages (see also reference 8).

49. Gama JA, Reis AM, Domingues I, Mendes-Soares H, Matos AM, Dionisio F: Temperate bacterial viruses as double-edged swords in bacterial warfare. PLoS One 2013, 8:e59043.

50. Fernandez-Lopez R, Del Campo I, Revilla C, Cuevas A, de la Cruz F: Negative feedback and transcriptional overshooting in a regulatory network for horizontal gene transfer. PLoS Genet 2014, 10:e1004171.

51. Morelli MJ, Ten Wolde PR, Allen RJ: DNA looping provides stability and robustness to the bacteriophage lambda switch. Proc Natl Acad Sci U S A 2009, 106:8101-8106.

52. Lawrence JG, Hendrix RW, Casjens S: Where are the pseudogenes in bacterial genomes?Trends Microbiol 2001, 9:535-540.

53**. Bobay LM, Touchon M, Rocha EPC: Pervasive domestication of defective prophages by bacteria.Proc Natl Acad Sci U S A 2014, accepted pending minor revisions.

Identification and study of hundreds of vertically inherited prophages. Most of these are partially degraded and evolve under purifying selection.

54. Campbell A: Defective Bacteriophages and Incomplete Prophages. In Regulation and Genetics. Edited by Fraenkel-Conrat H, Wagner RR: Springer US; 1977:259328. vol 8.]

55. Refardt D: Within-host competition determines reproductive success of temperate bacteriophages. The ISME Journal 2011, 5:1451-1460.

56. Bondy-Denomy J, Davidson AR: When a virus is not a parasite: the beneficial effects of prophages on bacterial fitness. J Microbiol 2014, 52:235-242. 
57. Bensing BA, Siboo IR, Sullam PM: Proteins PblA and PblB of Streptococcus mitis, which promote binding to human platelets, are encoded within a lysogenic bacteriophage. Infect Immun 2001, 69:6186-6192.

58. Hurst MR, Glare TR, Jackson TA: Cloning Serratia entomophila antifeeding genes-a putative defective prophage active against the grass grub Costelytra zealandica. J Bacteriol 2004, 186:5116-5128.

59. Yang G, Dowling AJ, Gerike U, ffrench-Constant RH, Waterfield NR: Photorhabdus virulence cassettes confer injectable insecticidal activity against the wax moth. J Bacteriol 2006, 188:2254-2261.

60. Shikuma NJ, Pilhofer M, Weiss GL, Hadfield MG, Jensen GJ, Newman DK: Marine tubeworm metamorphosis induced by arrays of bacterial phage tail-like structures. Science 2014, 343:529-533.

Describes an intriguing phage tail-like structure involved in inducing the metamorphosis of a marine tubewormby a bacterium. This is an interesting example of a non-antagonistic interaction between bacteria and eukaryotes mediated by phage-like particles.

61*. Rabinovich L, Sigal N, Borovok I, Nir-Paz R, Herskovits AA: Prophage excision activates Listeria competence genes that promote phagosomal escape and virulence. Cell 2012, 150:792-802.

Reports how a prophage induction does not lead to the production of virions and instead is used as a genetic switch by Listeria monocytogenesto promote escape from phagosomes.

62. Brussow H, Canchaya C, Hardt WD: Phages and the evolution of bacterial pathogens: from genomic rearrangements to lysogenic conversion. Microbiol Mol Biol Rev 2004, 68:560-602.

63. Sharples GJ, Ingleston SM, Lloyd RG: Holliday junction processing in bacteria: insights from the evolutionary conservation of RuvABC, RecG, and RusA. $J$ Bacteriol 1999, 181:5543-5550.

64. De Paepe M, Hutinet G, Son O, Amarir-Bouhram J, Schbath S, Petit MA: Temperate phages acquire DNA from defective prophages by relaxed homologous recombination: the role of Rad52-like recombinases. PLoS Genet 2014, 10:e1004181.

65. Veesler D, Cambillau C: A common evolutionary origin for tailed-bacteriophage functional modules and bacterial machineries. Microbiol Mol Biol Rev 2011, 75:423-433, first page of table of contents.

66. Alvarez-Martinez CE, Christie PJ: Biological diversity of prokaryotic type IV secretion systems.Microbiol Mol Biol Rev 2009, 73:775-808.

67. Guglielmini J, de la Cruz F, Rocha EP: Evolution of conjugation and type IV secretion systems. Mol Biol Evol 2013, 30:315-331.

68. Egan ES, Fogel MA, Waldor MK: Divided genomes: negotiating the cell cycle in prokaryotes with multiple chromosomes. Mol Microbiol 2005, 56:1129-1138.

69. Leiman PG, Basler M, Ramagopal UA, Bonanno JB, Sauder JM, Pukatzki S, Burley SK, Almo SC, Mekalanos JJ: Type VI secretion apparatus and phage tail-associated 
protein complexes share a common evolutionary origin. Proc Natl Acad Sci U $S$ A 2009, 106:4154-4159.

70. Winstanley C, Langille MG, Fothergill JL, Kukavica-Ibrulj I, Paradis-Bleau C, Sanschagrin F, Thomson NR, Winsor GL, Quail MA, Lennard N, et al.: Newly introduced genomic prophage islands are critical determinants of in vivo competitiveness in the Liverpool Epidemic Strain of Pseudomonas aeruginosa. Genome Res 2009, 19:12-23.

71. Rybakova D, Radjainia M, Turner A, Sen A, Mitra AK, Hurst MR: Role of antifeeding prophage (Afp) protein Afp16 in terminating the length of the Afp tailocin and stabilizing its sheath. Mol Microbiol 2013, 89:702-714.

72. Lang AS, Zhaxybayeva O, Beatty JT: Gene transfer agents: phage-like elements of genetic exchange. Nature Reviews Microbiology 2012, 10:472-482.

73. Nogueira $T$, Touchon $M$, Rocha EP: Rapid evolution of the sequences and gene repertoires of secreted proteins in bacteria. PLOS ONE 2012, 7:e49403.

74. Marchetti M, Capela D, Glew M, Cruveiller S, Chane-Woon-Ming B, Gris C, Timmers T, Poinsot V, Gilbert LB, Heeb P, et al.: Experimental evolution of a plant pathogen into a legume symbiont. PLoS Biol 2010, 8:e1000280.

75. Basler M, Ho BT, Mekalanos JJ: Tit-for-tat: type VI secretion system counterattack during bacterial cell-cell interactions. Cell 2013, 152:884-894.

76. Mougous JD, Cuff ME, Raunser S, Shen A, Zhou M, Gifford CA, Goodman AL, Joachimiak G, Ordonez CL, Lory S, et al:: A virulence locus of Pseudomonas aeruginosa encodes a protein secretion apparatus. Science 2006, 312:15261530.

77. Basler M, Pilhofer M, Henderson GP, Jensen GJ, Mekalanos JJ: Type VI secretion requires a dynamic contractile phage tail-like structure. Nature 2012, 483:182-186.

Figure legends.

Figure 1 - Chromosomal organization (top). (1) The E. coli circular chromosome is organized into 4 structured macrodomains (MD) and 2 unstructured flexible chromosomal regions (NS)[17]. (2) The macrodomainTer (MD-Ter, black) is preferentially located at the periphery of the nucleoid [25]. (3) MatPdefines the MDTerby binding to matSsequence motifs [34]. SlmA binds to DNA motifs frequent in MDOri and the flanking NS-regions to prevent chromosome fragmentation during septum formation[35]. (4) Chromosomal replication proceedsbi-directionally (black arrow) from a single origin ( $\mathrm{oriC}$, yellow) to the opposite termination site (dif, grey). The leading (resp. lagging) strands are represented in green (resp. red)and are different in terms of composition (GC skew), number of genes, and Chi and KOPS motifs [12]. (5) Presence of 
multiple replication forks in fast-growing bacteria produces a transient replicationassociated gene dosage effect that leads to selection of highly expressed genes (violet) near the origin of replication[23]. (6) KOPS (FtsK-orienting polar sequence, brown) are polarized motifs very frequent in the Ter-proximal regions. They orient the last stages of chromosome segregation[36].MGE accommodation(bottom).(1)Transposable prophageMu (green) integrates randomly in the genome, whereas most other prophages (red) integratemore frequently in the MD-Ter and the flanking MD-Left and Right. Pathogenicity islands (PAI, blue) are more frequent in the other half of chromosome (i.e. MD-Ori and NS-regions)[15]. (2) Mu forms a stable chromosomal domain. (3) Mobile elements using site-specific recombinases are concentrated in a few integrative hotspots. PAI integrated attRNA genes, whereas prophages also use other targets. (4) The occupancy rate and the number of integrative hotpots increase with the distance from the origin, in inverse relation with replication-associated gene dosage effects. (5)Prophages show avoidance of MatP and over-representation of KOPS that are relevant only at the prophage state in the context of the biology of the host. 


\section{Figure 2. Schematic representation of phage and conjugation-related}

domesticated elements.Top row:elements involved in bacteria-bacteria interactions or gene transfer: transducing phages, gene transfer agents (GTA), killer particles (defective phage particles), tailocins, type VI secretion systems (T6SS), type IV secretion systems (T4SS) involved in protein and DNA secretion and in DNA uptake (competence)[65,67]. Lower row: elements involved in interactions with Eukaryotes: Photorhabdus virulence cassettes (PVC) andantifeedingprophages (Afp) are toxic to certain eukaryotes[58,59]. Multi-MAC arrays containphage tail-like contractile structures and induce marine tubeworm metamorphosis[60]. Prophage-encoded platelet-binding factors which promote bacterial binding to human platelets and induce endovascular infection[47,48].T4SS from conjugative systems and T6SS derived from phages are used by pathogens and mutualists to secrete effectors to eukaryotic cells $[43,77]$. 